\title{
WHO recommendations on the composition of the 2015/16 influenza virus vaccines in the northern hemisphere
}

Eurosurveillance editorial team (eurosurveillance@ecdc.europa.eu) ${ }^{1}$

1. European Centre for Disease Prevention and Control (ECDC), Stockholm, Sweden

Citation style for this article:

Eurosurveillance editorial team. WHO recommendations on the composition of the $2015 / 16$ influenza virus vaccines in the northern hemisphere. Euro Surveill. 2015;20(9):pii=21048. Available online: http://www.eurosurveillance.org/ViewArticle.aspx?Articleld=21048

Article published on 05 March 2015

On 26 February 2015, the World Health Organization (WHO) published the recommendations on the composition of the trivalent and quadrivalent vaccines for use in the 2015/16 influenza season in the northern hemisphere [1].

WHO recommended changing two of the three strains in trivalent influenza vaccines for the next influenza season in the northern hemisphere: $\mathrm{H}_{3} \mathrm{~N}_{2}$ and influenza $B$. The chosen strains are the same as those recommended for this year's influenza season in the southern hemisphere.

WHO recommended that trivalent vaccines for use in the 2015/16 influenza season in the northern hemisphere contain the following:

- an A/California/7/2009 (H1N1)pdmo9-like virus;

- an A/Switzerland/9715293/2013 (H3N2)-like virus;

- a B/Phuket/3073/2013-like virus.

WHO also recommended that quadrivalent vaccines containing two influenza $B$ viruses should contain the above three viruses and a B/Brisbane/60/2008-like virus.

As in previous years, national or regional authorities approve the composition and formulation of vaccines used in each country and are responsible for making recommendations regarding the use of the vaccine.

\section{References}

1. World Health Organization (WHO). Recommended composition of influenza virus vaccines for use in the 2015-2016 northern hemisphere influenza season. Geneva: WHO. Feb 2015.

Available from: http://www.who.int/influenza/vaccines/virus/

recommendations/201502_recommendation.pdf?ua $=1$ 